\title{
NOTE ON (1) SAMPLES OF COFFEE CONTAINING ADDED STARCH ; (2) A SAMPLE OF ARTIFICIAL COFFEE BFRRIES.
}

\author{
By Cecil H. Cribi, B.Sc., F.I.C.
}

(Read at the Meeting, January 22, 1902.)

IN the course of last year, amongst the samples of coffee submitted to me under the Sale of Food and Drugs Acts, there was one which, on examination, was found to contain starch. Still more recently a second sample similarly adulterated has come into my hands. Judging from official records, this kind of adulteration is extremely rare in England, and I can find no recent mention of it.

The offence is such a clumsy form of sophistication, and so easy of detection, that it would hardly seem worth while to run the risk incurred by its committal; but the occurrence of two cases in such a short time in the same district led ne to think it desirable to give the matter the publicity afforded by our Journal. It is just possible that the offence occurs more frequently than is indicated by the statistics available, but owing to the adulterant occurring in coffee and chicory properly labelled as a "mixture," it may have been allowed to pass unnoticed, the analyst concluding, as did the vendor in one of the cases, that notification as a "mixture" would cover the addition of anything whatever. Of the two samples under discussion, one was actually purchased as "Coffee Mixture," the other being bought as "Coffee and Chicory." In the former case it became necessary to prove that mixed coffee meant coffee mixed with chicory, and with nothing else. As far as it was possible to ascertain, opinion in the trade was unanimous on this point, and the admixture of starch was declared to be a quite unheard-of thing. In the course of my inquiries I was given a sample of artificial coffee beans, which I was informed came over from America a few years ago, but met with no sale here. This is somewhat surprising considering the enormous extent to which coffee is adulterated in America with various mixtures, often made up into berries, consisting largely or entirely of starch. Possibly one explanation is that the sale of such a mixture is not only an offence against the Adulteration Acts, but also against the Inland Revenue Acts, which make it illegal (c. 41, s. 6) to sell, expose for sale, offer or keep ready for sale, or deliver, coffee containing anything other than chicory, unless done up in packets of a certain size and bearing a label stating the nature of the substance used and the amount of duty paid. For convenience of comparison the same analytical determinations, with one exception, have been made on each of the three samples, and the results are given in the table: 


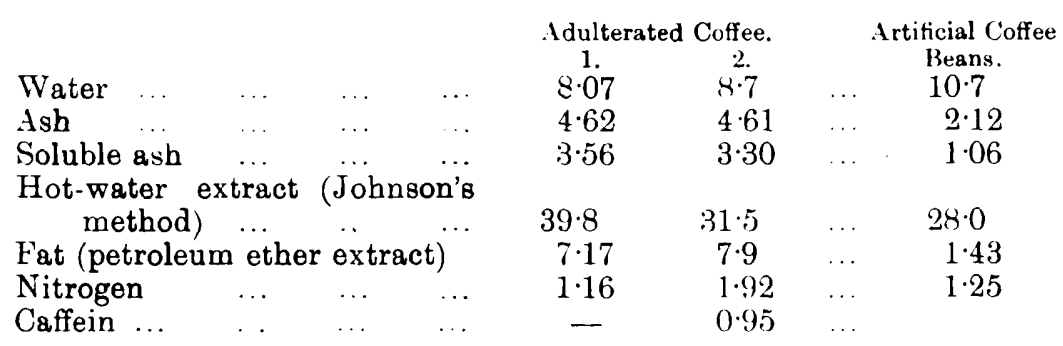

In Sample No. 1 the microscope revealed only a small proportion of sturch, which certainly did not exceed 5 per cent., but was far more than could be due to accident alone. It was almost entirely arrowroot, but there were also a few granules present having the characters of wheat, sago, and potato respectively. The condition of the granules pointed to their having been added after roasting.

In Sample No. 2 about 15 per cent. of starch appeared to be pregent, and it consisted entirely of sago. The artificial beans appeared to consist mainly of starch, probably of leguminous origin, but the granules had suffered considerably by the heat to which they had evidently been exposed.

The estimation of the starch by chemical means is a matter of some difficulty, and for the purposes of the prosecution I was content to rely mainly on the microscopical examination, comparing the sample with mixtures of known composition, made up, of course, with the same kind of starch.

The direct estimation of the starch by the diastase method after extraction with alcohol and ether would appear to be the most promising, but the process is a long and tedious one, and time has prevented me from applying it to the present samples.

In the case of Sample No. 2 a determination of the cupric reducing power of the mixture after extracting with petroleum ether, alcohol, and water (a very lengthy process when much chicory is present), and hydrolysing under pressure with hydrochloric acid, gave a figure equivalent to 16.9 per cent. of starch-a satisfactory confirmation of the amount as determined by the microscope; here, however, the sample only contained a small proportion of chicory.

With Sample No. 1 an attempt was made to shorten the process by estimating the cupric reducing power after the mixture had been heated with hydrochloric acid under pressure without previous extraction, and deducting from the figure so obtained the reducing power of the hot-water extract after the latter had been inverted by acid, but the result was hopelessly beyond the truth.

The spurious coffee berries exhibit an artful variation in shape and size, but are at once distinguished from real coffee by the absence of any remains of the "parchment" in the longitudinal groove, and also by the fact that they sink in water, whereas coffee berries float. They are free from any aniline dye and from any mineral colouring matters like venetian red.

In conclusion, I should like to suggest that local authorities might with advantage pay more attention to mixtures of coffee and chicory. On the whole, my own experience leads me to believe that intentional adulteration is extremely rare; but chicory itself is by no means above suspicion, and the attempt may at any time be made to introduce into the English market American preparations such as that just described. 


\section{Discussion.}

Mr. BAKER said that one large firm on the Continent, who were makers of crystal malt, made a practice of incorporating this crystal malt with a certain amount of sugar, and from 10 to 15 per cent. of coffee, the mixture being then moulded into the form of beans and sold as coffee; and he believed that a very large business was done by the firm in that particular article. Artificial coffee beans so prepared would contain no free starch, but dextrinous particles would be present, which probably would afford a ready means of recognising the article. In the course of a recent investigation he had found that the principal constituent of the coffee berry substance was a manno-arabinose or manno-xylose, which on hydrolysis yielded mannose in quantities of from 80 to 90 per cent. Chicory, he believed, yielded no mannose on hydrolysis, and possibly a quantitative estimation of coffee in a mixture of coffee and chicory might be arrived at on the basis of the amount of mannose yielded on hydrolysis, which could be readily determined by means of the hydrazone test (compare Baker and Pope, Chem. Soc. Trans., 1900, vii., 704).

Mr. HeHner thought that probably a simple explanation of the occurrence of starch in the two samples referred to in the first paper might be, not that there had been deliberate adulteration, but that the mill in which the coffee had been ground had been used previously for grinding some.starchy material. Such occurrences were not uncommon, and were, indeed, very apt occasionally to be met with in establishments where the appliances were not absolutely perfect.

Mr. Richmond said that a satisfactory method was much to be desired for the examination of coffee after it had been made into a beverage. The matier was a very difficult one to deal with, especially in cases in which milk had been added. He thought, however, that an idea of the volume of milk added might be obtained from the fact that milk contained a nucleo-proteid, the quantity of which could be estimated with comparative ease from a determination of phosphorus, a constituent always present in combination in such proteids. From this determination the milksugar could be approximately deduced, and its effect on the estimations indicating carbohydrates allowed for.

The President said that a curious method of imitating coffee berries, and also even wheat, which he had found to be practised by the natives in India, consisted simply in moulding ordinary mud into the shape of the different grains. He thought that probably Mr. Hehner's suggestion would be found to account for the presence of the starch in sample No. 1 at any rate. In sample No. 2, however, the proportion of starch-namely, 15 per cent.- - seemed rather high to be accounted for in that way.

Mr. E. W. VoELcker said that, in the case of a sample which afterwards proved to have been actually ground in the presence of the Food and Drugs Inspector who purchased it, he had reported the presence of from 40 to 50 per cent. of chicory. The beans must have consisted practically of 50 per cent. of chicory and sugar with about 50 per cent. of coffee. 